\title{
Voice Characteristics of Kannada Speaking 3 to 5 Year Old Children with Repaired Cleft of Lip and Palate
}

\author{
Deepthi $\mathrm{KJ}^{1 *}$ and Pushpavathi $\mathbf{M}^{2}$ \\ ${ }^{1}$ Research Fellow, Department of Speech-Language Pathology, All India Institute of Speech and Hearing, Mysore, Karnataka, India \\ ${ }^{2}$ Professor, Department of Speech-Language Pathology, All India Institute of Speech and Hearing, Mysuru, Karnataka, India
}

Submission: July 24, 2018; Published: July 27, 2018

*Corresponding author: Deepthi K J, Research Fellow, Department of Speech-Language Pathology, All India Institute of Speech and Hearing, Mysore, Karnataka, India; Email: kjdeepthi86@gmail.com

\begin{abstract}
There is an increase of children with cleft of lip and palate in India. However the number of studies investigating the voice characteristics of children with CLP in any of the Indian languages is sparse. Thus the current study is aimed at investigating the voice characteristics viz., fundamental frequency, intensity, jitter and shimmer in 3 to 5 year old native Kannada speaking children with repaired cleft of lip and palate (RCLP). Twenty children with RCLP were considered for the study that were divided into 3 to 4 year old and 4 to 5 year old groups. Twenty age matched typically developing children were also considered for the study. Phonation of vowel /a/ was recorded for each child and analysed using Praat (5.4.14) software. Appropriate statistical analysis was done to compare the results between groups and across ages. The results revealed that only fundamental frequency was statistically different between the groups however age effect was not seen for the same. The remaining parameters viz., intensity, jitter percentage and shimmer percentage were not found to be statistically significant between groups and across ages as well. The reasons for the same are discussed.
\end{abstract}

Keywords: Voice; Acoustic analysis; Kannada language

Abbreviations: TDC: Typically Developing Children; CLP: Cleft of Lip and Palate; RCLP: Repaired Cleft of Lip and Palate; WHO: World Health Organization; TQS: Ten Question Screening; Fundamental frequency: F0; Hz: hertz; Intensity: Int; dB: decibels; Jitter\%: jitta; Shimmer\%: Shim

\section{Introduction}

Cleft of lip and palate (CLP) is a craniofacial deformity which occurs due to cessation of fusion of palatal shelves during the first trimester of pregnancy. It is caused due to various extrinsic and intrinsic factors and reported to have a prevalence of 1 in 650 live births in Indian subcontinent [1]. It has also been reported that there is an increase in the number of children reported with CLP every year in India [2]. Children with CLP present with various speech and language disorders such as articulatory errors, compensatory articulation, poor receptive and/or expressive language skills, velopharyngeal dysfunction, nasal air emissions and voice disorder etc., [3].

Voice disorder has been investigated quite often in individuals with CLP [4-6]. Approximately $5 \%$ to $21 \%$ of children with CLP are affected by voice disorder with varying degree of severity [7-12]. Voice disorder is reported to be a factor influencing the quality of cleft palate speech [4]. There have been various studies which investigated the presence of voice disorders and attempted to explain its underlying pathophysiology in individuals with CLP. In addition, few other studies investigated the acoustic and aerodynamic aspects of voice in the same population.

One of the early studies on voice in children with CLP, investigated forty three children with associated hoarseness of voice using laryngoscopy [13]. It was reported that out of 43 children 8 children did not present with hoarseness of voice at the time of laryngoscopic investigation. Though the reason for the same is not proposed, it can be speculated that there was spontaneous reduction in the hoarseness in these children. Among the remaining children, only 32 children were examined using laryngoscope. Out of them, around 84\% were found with vocal cord problems such as, unilateral vocal cord nodules, bilateral vocal cord nodules, posterior glottal chink, bilateral vocal cord hypertrophy, slight anterior edema and improper vocal cord approximation. The authors opined that if a child with CLP presents with hoarseness of voice at the beginning, speech therapy is contradicted in them. Also presence of vocal pathologies specifically vocal nodules is a strong indicator of improper velaopharyngeal function. Secondary procedures to correct velopharyngeal inadequacy in such cases was advised. 
The relationship between the laryngeal dysfunction and hypernasality in adults with repaired cleft was also investigated [14]. It was reported in the study that only adults with significant hypernasality exhibited abnormal laryngeal function. They concluded that the abnormal laryngeal valving was used as a compensatory mechanism by individuals with velopharyngeal incompetency.

A longitudinal study investigated 15 children with CLP who had undergone soft palate closure at the age of 6-8 months and hard palate closure at the age of 8-9 years of age [7]. The study reported that around $47 \%$ of children with CLP were dysphonic by the age of five years and by the age of nine years only $27 \%$ of the children were mildly dysphonic. According to the study, the voice problem reduced to mild degree at older age due to the complete closure of the residual cleft.

The relationship of laryngeal function, voice, nasoendocopic and aerodynamic aspects of velopharyngeal dysfunction was investigated [6]. The investigation found a strong correlation between laryngeal function, voice and sub-glottal air pressure. The authors concluded that few of the children with CLP compensate for poor velopharyngeal valving by increasing the effort or by abnormal laryngeal valving. This increased respiratory effort may be the cause of vocal abuse [15].

A study investigated the voice characteristics in ten children between the age of 6.8 to 11.10 years of age with VPI. The study revealed a direct correlation between jitter and perceived nasality and on the other hand shimmer was found to be directly correlated with perceived hoarseness [16]. Few other studies investigating the acoustic parameters of voice have reported that the voice of children with CLP is characterised by the presence of frequency instability, high intensity, abnormal formant distribution and abnormal spectrograms [16-18].

Further a study compared the jitter and shimmer parameters obtained by "Vaghmi speech and voice systems" software between pre-operative group and post-operative groups [19]. The study consisted of forty children with CLP between 0 to 10 years of age. The study revealed that the shimmer values of pre-operative and post-operative children with CLP was higher than their respective control groups though it was not statistically significant. Further there was no statistical difference between pre-operative and post-operative children with CLP in terms of perturbation parameters. The study revealed that the perturbation parameters were not sensitive enough in identifying the presence of voice disorders in children with CLP. The reason for such a conclusion was because they observed jitter values to be more sensitive than shimmer values on certain occasions and also the post-operative perturbation values were higher than pre-operative condition. The investigators reckoned that further research was needed to ascertain the same using various other perturbation measures.

Additionally a study investigated the voice perturbation measures in 49 Kannada speaking, 7 to 13 year old children with
CLP [20]. Praat software was used to record the phonation of children and analyse the same to obtain perturbation measures. It was reported that the jitter and shimmer measures obtained in children with CLP were comparatively higher than the control group. However the values of both groups were within the normal range. It can be speculated from this study that as the children were between 7 to 13 years and had attended speech therapy they would have overcome the velopharngeal incompetency leading to statistically insignificant perturbation measures. However, they were still not using the laryngeal mechanism optimally due to which the perturbation measures continued to be higher in children with CLP than the control group.

Thus the literature revealed that individuals with CLP often have voice disorders which could be a compensatory mechanism to overcome the velopharyngeal dysfunction or due to underlying vocal cord pathology. Voice disorder is not only present in children with CLP but also in adults with CLP and the severity of the same varied. Vocal disorder is dependent on the severity of hypernasality, respiratory effort and reduces as the velopharyngeal function improves. However the studies investigating the acoustic parameters of voice have been indecisive. This could be due to various factors such as age, race, stimulus, software used for sample collection and analysis. Age of primary and secondary surgeries and speech therapy varied in the previous studies which also have a significant effect on voice of children with CLP.

Therefore the current study is aimed at investigating the voice of 3 to 5 year old native Kannada speaking children with repaired cleft of lip and palate (RCLP). The first objective of the study was to investigate characteristics of voice in-terms of fundamental frequency $(\mathrm{Hz})$ and intensity $(\mathrm{dB})$ in children with RCLP and TDC and to compare the same between groups and across ages. The second objective was to investigate the perturbation parameters viz., jitter percentage and shimmer percentage in children with RCLP and TDC and to compare the same between groups and across ages.

Jitter is the cycle to cycle variation in frequency and shimmer is cycle to cycle variation in intensity of sound wave [21]. A jitter percentage of $0.68 \%$ and shimmer percentage of $0.45 \%$ for vowel /a/ has been reported for Indian children between 5 to 10 years of age [22]. Jitter percentage of 0.5 to $1.0 \%$ and a shimmer percentage of $<3 \%$ is considered an acceptable value in adults [21]. These parameters are best studied by analysing steady state vowel. The current study focussed on recording and analysing vowel /a/ as it is considered to be acoustically most consistent $[23,24]$.

\section{Method}

\section{Participant Selection}

Forty native Kannada speaking children between the ages of 3 to 5 years were considered for the study. Among them twenty were children with RCLP. They were further divided based on age into two groups viz., 3 to 4 year old group and 4 to 5 year old group. Children with RCLP were selected based on conve- 
nience sampling from Unit for Structural and Oro-Facial Anomalies at Department of Clinical Services of All India Institute of Speech and Hearing, Mysore. Children in RCLP groups had been operated for cleft before 1.5 years of age. None of the children attended speech and language therapy pre or post-surgery.

Remaining twenty children were typically developing children (TDC) who were also divided into 3 to 4 year old and 4-5 year old age groups. They were selected from residential areas, Anganwadis and pre-schools from various areas in Mysore. All children had to pass WHO Ten Questions Screen (TQS), for childhood disability [25]. Any child with concomitant syndromes, upper respiratory tract infections, hearing loss, history of middle ear infections, poor intelligence, cleft of lip alone, non-native Kannada speakers were eliminated from the investigation. The parents of the children provided written consent before including their children in the investigation. The study was conducted according the ethical guidelines of the All India Institute of Speech and Hearing [26].

\section{Procedure}

The investigator built rapport with each child before beginning the investigation. Following this the child was made to sit comfortably with the torso erect in a quiet room on a chair. The child was made to wear a headphone with a built in unidirectional microphone. The distance between the microphone and the mouth was maintained at $10 \mathrm{~cm}$. The investigator then demonstrated a sustained phonation of vowel /a/ at a comfortable pitch and loudness after a deep inhalation. The child was then instructed to carry out the same. After the investigator was convinced that the child was able to carry out the activity as demonstrated, the data was recorded. The child was asked to phonate vowel /a/ three times with a inter stimulus gap of 3 seconds. The phonation was recorded using Praat software (5.4.14) [26] installed in a Dell Inspiron laptop and saved for later analysis.

\section{Analysis}

The sample of each child was analysed individually using Praat software (5.4.14) [27]. This was done by selecting a 3 second steady state portion of the vowel sample and analysing it. Data about fundamental frequency (F0 in $\mathrm{Hz}$ ), intensity (Int in $\mathrm{dB}$ ), jitter\% and shimmer\% were collected and tabulated for further analyzed within and across groups.

\section{Results}

\section{Fundamental Frequency and Intensity Between Groups and Across Ages}

Shapiro-Wilk Test of normality on the fundamental frequency and intensity data revealed that both RCLP and TDC followed normal distribution. The descriptive statistics of Fundamental frequency ( $\mathrm{F} 0$ in $\mathrm{Hz}$ ) and Intensity (Int in $\mathrm{dB}$ ) is presented in Table 1. It was noted from Table 1 that the mean F0 ranged from $290 \mathrm{~Hz}$ to $307 \mathrm{~Hz}$ in children with RCLP. However in the TDC group the F0 ranged from $260 \mathrm{~Hz}$ to $237 \mathrm{~Hz}$. Also it can be noticed that the mean fundamental frequency was higher in 3-4 and 4-5 year old children with RCLP than the corresponding TDC groups. On the other hand, the intensity range in both RCLP and TDC groups was limited. It can be noted that the while the 3-4 year old children with RCLP had higher intensity values the opposite was true in 4-5 year old groups.

Table 1: Mean, SD and Median across RCLP and TDC for Fundamental frequency ( $\mathrm{FO}$ in $\mathrm{Hz}$ ) and Intensity (Int in $\mathrm{dB}$ ).

\begin{tabular}{|c|c|c|c|c|c|c|}
\hline & Group & Age & $\mathbf{N}$ & Mean & SD & Median \\
\hline \multirow{6}{*}{ F0 } & \multirow{3}{*}{ RCLP } & $3-4$ & 10 & 296.78 & 31.67 & 307.18 \\
\hline & & $4-5$ & 10 & 290.43 & 31.58 & 292.27 \\
\hline & & Total & 20 & 293.60 & 30.95 & 300.09 \\
\hline & \multirow{3}{*}{ TDC } & $3-4$ & 10 & 263.56 & 22.40 & 260.66 \\
\hline & & $4-5$ & 10 & 273.27 & 42.58 & 266.30 \\
\hline & & Total & 20 & 268.41 & 33.49 & 261.06 \\
\hline \multirow{6}{*}{ Int } & \multirow{3}{*}{ RCLP } & $3-4$ & 10 & 58.16 & 5.85 & 55.85 \\
\hline & & $4-5$ & 10 & 55.33 & 4.94 & 55.25 \\
\hline & & Total & 20 & 56.74 & 5.47 & 55.78 \\
\hline & \multirow{3}{*}{ TDC } & $3-4$ & 10 & 54.41 & 4.29 & 52.79 \\
\hline & & $4-5$ & 10 & 56.18 & 4.62 & 55.97 \\
\hline & & Total & 20 & 55.29 & 4.44 & 54.78 \\
\hline
\end{tabular}

Perturbation Measurements Between Groups and Across Ages

Shapiro-Wilk Test of normality on the jitter\% and shimmer\% data revealed that both RCLP and TDC followed normal distribution the descriptive statistics of jitter\% (jitta) and shimmer\% (shim) has been tabulated in Table 2.

Table 2: Mean, SD and Median across RCLP and TDC for Jitter\% (jitta) and Shimmer\% (shim).

\begin{tabular}{|c|c|c|c|c|c|c|}
\hline & Group & Age & $\mathbf{N}$ & Mean & SD & Median \\
\hline \multirow{6}{*}{ Jitt } & \multirow{3}{*}{ RCLP } & $3-4$ & 10 & 0.45 & 0.13 & 0.46 \\
\hline & & 4-5 & 10 & 0.54 & 0.25 & 0.45 \\
\hline & & Total & 20 & 0.50 & 0.20 & 0.45 \\
\hline & \multirow{3}{*}{ TDC } & 3-4 & 10 & 0.38 & 0.05 & 0.37 \\
\hline & & $4-5$ & 10 & 0.40 & 0.19 & 0.39 \\
\hline & & Total & 20 & 0.39 & 0.14 & 0.38 \\
\hline \multirow{6}{*}{ Shim } & \multirow{3}{*}{ RCLP } & $3-4$ & 10 & 9.09 & 5.17 & 7.79 \\
\hline & & $4-5$ & 10 & 10.28 & 4.25 & 10.35 \\
\hline & & Total & 20 & 9.68 & 4.65 & 9.27 \\
\hline & \multirow{3}{*}{ TDC } & $3-4$ & 10 & 9.92 & 4.26 & 9.42 \\
\hline & & $5-4$ & 10 & 7.76 & 4.79 & 7.20 \\
\hline & & Total & 20 & 8.84 & 4.55 & 9.40 \\
\hline
\end{tabular}

It was noted from Table 2 that within the perturbation measures mean jitter \% was higher in 3-4 and 4-5 year old children with RCLP than the respective TDC groups. The shimmer \% was found to be higher in 4-5 year RCLP than TDC however, shimmer $\%$ was minimally higher in 3-4 year old TDC than in RCLP group.

To identify whether there is any statistical difference between RCLP and TDC groups with respect to the four pa- 


\section{Global Journal of Otolaryngology}

rameters, two-way MANOVA was done. The test indicated that there is a significant difference between RCLP and TDC groups in all four parameters $[\mathrm{F}(4,33)=3.805, \mathrm{p}<0.05]$ however there was no significant difference noted between the age groups $[F(4,33)=0.514, p>0.05]$. Further, there was no significant interaction noted between groups and age $[F(4,33)=0.560, p>0.05]$. Subsequent ANOVA revealed presence of significant group effect in fundamental frequency alone $[F(1,36)=5.880$, $p<0.05$, effect size $=0.140]$ whereas other effects were not noted with respect to intensity and perturbation measures.

\section{Discussion}

The current study revealed that there is overall significant difference between the RCLP and TDC groups with respect to fundamental frequency, intensity and perturbation parameters. Similar findings have been reported in previous studies $[17,18]$. Children with RCLP in the current study had persistent velopharyngeal dysfunction. This could have promoted them to adopt compensatory laryngeal function. Compensatory laryngeal function would have initiated active vocal resistance leading to hyperfunctional use of voice which in turn resulted in poor voice characteristics $[28,20]$. The fundamental frequency of RCLP was significantly higher compared to TDC group. Contradictory findings have been reported by previous studies [29]. Persistent VPD in children with RCLP in the current study could have created an imbalance in the vocal tract valve actions $[14,30]$. Specifically there would be an increase effort in the laryngeal valve muscles [6]. This could have led to increase in the stiffness of vocal folds, consequently increasing the fundamental frequency.

Intensity values were not found to be statistically different between RCLP and TDC group overall. However intensity value was found to be higher in 3-4 year old children with RCLP compared to TDC. Findings of the current study does not support the previous findings [31-33]. The children in RCLP group of the current study would have adopted the use increased loudness to be make their speech more intelligible and acceptable to their listeners. Also language and culture might have had an effect on the use of loudness by children with RCLP. The jitter and shimmer values were not found to be significantly different between RCLP and TDC groups. However it was observed that children with RCLP had higher perturbation values compared to TDC groups. Previous study has also reported similar values in their investigation however the age group considered in their study varied form the current study [20]. The perturbation parameters are dependent on the neuromuscular activity and aerodynamic events at the level of glottis. They are also directly related to the severity of VPD [28]. As the children with RCLP of the current study had varying degree of cleft, the velopharyngeal function post-surgery would also have varied greatly. Thus, resulting in greater perturbation values in children with RCLP.

\section{Conclusion}

The current study revealed the presence of difference in fundamental frequency between RCLP and TDC group. The same was not true with respect to intensity, jitter and shimmer. It can be speculated that early closure of cleft could have resulted in such a finding. However, the perturbation values were found to be higher in children with RCLP probably due to the persistent VPD. If the children with RCLP had attended speech therapy post-surgery, the velopharyngeal closure might have improved, which might have had a positive influence on the perturbation measures.

\section{Acknowledgement}

The authors would like to acknowledge the Dr.S.R.Savithri, Director, All India Institute of Speech and Hearing, Mysore for extending her support to conduct the research. We would also like to wholeheartedly thank all the participants of the study and their parents for their consent.

\section{References}

1. Raju S (2000) In search of a smile: Study of children born with cleft lips and palates in India. Mumbai, India: Impact India Foundation, Mumbai.

2. Shrivatsav S (2013) Parents still don't bring cleft lip, palate kids for treatment. Times of India.

3. D 'Antonio LL and Scherer NJ. Communication disorders associated with cleft palate. In: Losee J, Kirschner R, editors. Comprehensive cleft care. illustrate. New York: Mc Graw Hill Professional; 2008. p. 1166.

4. Mc Donald ET, Baker HK (1951) Cleft palate speech: An integration of research and clinical observation. J Speech Hear Disord 16(1): 9-20.

5. Marks C, Barkert K and Tarpy M (1971) Prevalence of perceived acoustic deviations related to laryngeal function among subjects with palatal anomalies. Cleft Palate J 8: 201-210.

6. D'Antonto L, Muntz H, Province M and MarsH J (1988) Laryngeal voice findings in patients with velopharyngeal dysfunction. Laryngoscope 98: 432-438.

7. Lohmander Agerskov A, Soderpalm E, Friede H and Lilja J (2009) A longitudinal study of speech in 15 children with cleft lip and palate treated by late repair of the hard palate. Scand J Plast Reconstr Surg Hand Surg 29: 21-31.

8. Bressmann T, Sader R, Whitehill TL, Awan SN and Zeilhofer H et.al (2000) Nasalance distance and ratio: Two new measures. Cleft PalateCraniofacial J 37(3): 248-256.

9. Hocevar-Boltezar I, Jarc A and Kozelj V (2006) Ear, nose and voice problems in children with orofacial clefts. J Laryngol Otol 120(4): 276281.

10. Hamming K, Finkelstein M and Sidman J (2009) Hoarseness in children with cleft palate J Otolaryngol Neak Surg 140: 902-906.

11. Robison J and Otteson T (2011) Prevalence of hoarseness in the cleft palate population. Arch Otolaryngol ogy - Head Neck Surg 137: 74-77.

12. Prathanee B, Thanawirattananit P and Thanaviratananich S (2013) Speech, language, voice, resonance and hearing disorders in patients with cleft lip and palate J Med Assoc Thai 96: 71-80.

13. Mc Williams BJ, Bluestone CD and Musgrave RH (1969) Diagnostic implication of vocal cord nodules in children with cleft palate. Laryngoscope 79(12): 2072-2080.

14. Leder S and Lerman J (1985) Some acoustic evidence for vocal abuse in adult speakers with repaired cleft palate. Laryngoscope 95(7 Pt 1): 837-840.

15. Warren D, Woop M and Radley D (1969) Respiratory volumes in normal and cleft palate speech. Cleft Palate J 6: 449-460. 
16. Zajac D and Linville R (1989) Voice perturbations of children with perceived nasality and hoarseness. Cleft Palate J 26: 226-232.

17. Kataoka R, Warren DW, Zajac DJ, Mayo R and Lutz RW (2001) The relationship between spectral characteristics and perceived hypernasality in children. J Acoust Soc Am 16: 205-210.

18. Jiang C, Whitehill TL, Mc Pherson B and Ng ML (2015) Consonant accuracy in Mandarin speaking children with repaired cleft palate. Int Pediatr Otorhinolaryngol [Internet] 79(12): 2270-2276.

19. Liz A and Jayashree (2012) V Perturbation In Voice Of Children With Cleft Lip And / Or Palate 6: 52-57.

20. Attuluri N, Pushpavathi M, Pandey P and Mahapatra S (2017) Voice Perturbations in Repaired Cleft Lip and Palate.

21. Zwetsch I, Fagundes R, Russomano T and Scolari D (2006) Digital signal processing in the differential diagnosis of beningn larynx diseases. Porto Alegre 16(3):109.

22. Shruthi L and Satish (2015) K Normative Values for PRAAT in the Age Range of 5-10 Years Old Typically Developing Children. Lang India 15(5): 350-359.

23. Doherty ET (1975) Evaluation of selected acoustic parameters for use in speaker identification. Acoust Soc Am 58(S107):1121.

24. Grellet M, Pereira JC and Rosa MO (2002) Standardization of acoustic measures of the normal voice Braz J Otorhinolaryngol 68: 540-544.

25. Singhi P, Kumar M, Malhi P and Kumar R (2007) Utility of the WHO Ten Questions Screen for Disability Detection in a Rural Community-the North Indian Experience. J Trop Pediatr 53(6): 383-387.

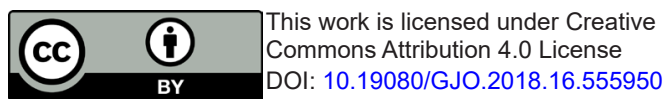

26. Venkateshan S and Basavraj V (2009) Ethical guidelines for biobehavioural research involving human subjects Mysore: All India Institute of Speech and Hearing p.23.

27. Boersma P and Weenink D Praat Amsterdam (2001).

28. Villafuerte-Gonzalez R, Valadez-Jimenez VM, Hernandez-Lopez X and Ysunza PA (2015) Acoustic analysis of voice in children with cleft palate and velopharyngeal insufficiency. Int J Pediatr Otorhinolaryngol 79(7): 1073-1076.

29. Tarlow (1970) A comparative study of the speak- ing fundamental frequency characteristics in children with cleft palate Cleft Palate -Craniofacial J pp. 696-705.

30. Kawano M, Isshiki N, Honjo I, Kojima H and Kurata K et.al (1997) Recent progress in treating patients with cleft palate. Folia Phoniatr Logop 49:117-138.

31. Cotton JC (1940) A study of certain phoniatric resonance phenomena. J Speech Hear Disord 5: 289-293.

32. Weiss AI (1954) Oral and nasal pressure levels as related to judged severity of nasality Purdue.

33. Morris HL (1968) Etiological bases for speech problems. In: Spriestersbach DC, Sherman DH, Curtis JF, editors. Cleft Palate and Communication. Academic Press, New York:, India pp. 291.

\section{Your next submission with Juniper Publishers will reach you the below assets}

- Quality Editorial service

- Swift Peer Review

- Reprints availability

- E-prints Service

- Manuscript Podcast for convenient understanding

- Global attainment for your research

- Manuscript accessibility in different formats

( Pdf, E-pub, Full Text, Audio)

- Unceasing customer service

Track the below URL for one-step submission https://juniperpublishers.com/online-submission.php 